\title{
NMDA Receptor Function and Human Cognition: The Effects of Ketamine in Healthy Volunteers
}

\author{
Anil K. Malhotra, M.D., Debra A. Pinals, M.D., Herbert Weingartner, Ph.D., Karen Sirocco, M.A., \\ C. David Missar, Ph.D., David Pickar, M.D., and Alan Breier, M.D.
}

A rapidly growing body of preclinical data has implicated the glutamatergic N-methyl-d-aspartate (NMDA) receptor in memory and other cognitive processes. There is comparatively less information about this receptor system in human cognition. We examined the effects of subanesthetic doses of ketamine, a noncompetitive NMDA receptor antagonist, on two forms of memory, free recall and recognition, as well as attention and behavior in a doubleblind, placebo-controlled, 1-hour infusion in 15 healthy volunteers. Ketamine produced decrements in free recall, recognition memory, and attention. In addition, ketamine induced a brief psychosis in our healthy volunteers marked by thought disorder and withdrawal-retardation. Ketamineinduced memory impairments were not accounted for by changes in subject's attention and were not significantly related to psychosis ratings. These data suggest that the NMDA receptor plays a direct role in two types of explicit memory. The implications of these data for the pathophysiology of schizophrenia are discussed. [Neuropsychopharmacology 14:301-307, 1996]
KEY WORDS: Ketamine; Cognition; Memory; Psychotic disorders; Receptors, N-methyl-d-aspartate,

Receptors, glutamate

Several lines of evidence have suggested that the glutamatergic $\mathrm{N}$-methyl-d-aspartate (NMDA) receptor is critically involved in cognition. Studies in laboratory animals have demonstrated that NMDA receptor antagonists disrupt learning (Shapiro and Caramanos 1990; Maurata and Kawasaki 1993), immediate recall (Ohno et al. 1994), and long-term retention (Lee et al. 1993), whereas NMDA receptor agonists improve memory retention (Flood et al. 1992). In addition, NMDA receptor antagonists disrupt the induction of long-term

From the Experimental Therapeutics Branch (AKM; DAP; DM; DP; AB), National Institute of Mental Health, Bethesda, MD; and the Division of Intramural Clinical and Biological Research (HW;KS), National Institute on Alcohol Abuse and Alcoholism, Bethesda, MD.

Address correspondence to Anil Malhotra, M.D., Experimental

Therapeutics Branch, National Institute of Mental Health, 9000 Rockville Pike Building 10, Room 4N212, Bethesda, MD 20892.

Received February 27, 1995; revised June 14, 1995; accepted June 22, 1995 . potentiation (LTP) in the hippocampus (Harris et al. 1984; Abraham and Mason 1988), a process of synaptic facilitation (the enhancement of postsynaptic response to presynaptic input) that may underlie the mechanism of learning and memory (Morris et al. 1986). Given the methodological and theoretical limitations of studying cognitive function in animals, it is difficult to extrapolate these data into humans, and studies examining the role of NMDA receptor in mediating human cognition are needed.

Human studies of NMDA receptor function have been limited by the lack of suitable pharmacological probes. Phenylcyclidine (PCP) and dizolcipine (MK801 ), potent noncompetitive NMDA receptor antagonists, have proven too toxic for human use (Olney et al. 1989). One strategy that has proven useful for the study of NMDA function is administration of subanesthetic doses of the "dissociative" anesthetic ketamine. Like PCP and dizolcipine, ketamine binds to a site within the ion channel of the NMDA receptor to inhibit calcium influx (Zukin and Zukin 1979). Clinically ketamine produces minimal cardiac and respiratory effects, and its 
anesthetic and behavioral effects remit soon after administration (Pandit et al. 1980; Moretti et al. 1984).

Prior studies of the effects of subanesthetic doses of ketamine have reported impairments in several cognitive domains, including attention and memory (Harris et al. 1975; Ghoneim et al. 1985; Oyte et al. 1992; Krystal et al. 1994). A number of unresolved issues, however, confound the interpretation of these studies. First, ketamine may disrupt attention, and it remains unclear whether ketamine-induced effects on other cognitive domains represent direct effects of ketamine or are secondary to attentional disturbances. Second, ketamine produces a psychosis in humans (Krystal et al. 1994) that may be responsible for the changes in cognitive function. Finally, methodological considerations such as the dose of ketamine, administrative paradigm, small sample sizes, and the lack of a placebo condition make interpretation of data from previous studies difficult.

In the present study we examined the effects of a placebo-controlled, double-blind, 1-hour infusion of subanesthetic doses of ketamine on cognition in healthy volunteers. The hypothesis to be tested was that ketamine would impair memory and attention and that these effects would be independent of each other and unrelated to ketamine's psychotomimetic effects.

\section{METHODS}

\section{Subjects}

Fifteen subjects ( 12 males, 3 females; mean age $27.9 \pm$ 7.1) were recruited through the National Institutes of Health normal volunteer program and participated in the study. All subjects were free of psychiatric disorders as determined by structured diagnostic interview [Schedule for Affective Disorders and Schizophrenia (SADS); Endicott and Spitzer 1978] and were in good health as determined by physical exam, electrocardiogram, and laboratory testing including liver and thyroid function tests and urinalysis.

\section{Procedure}

Each subject participated in two double-blind test days: one involving ketamine infusion and the other a placebo (saline) infusion. The order of ketamine and placebo was randomized and test days were separated by at least one day. Subjects fasted after midnight on each study day. On the morning of each study day bilateral antecubital intravenous lines were inserted. Sixty minutes after IV placement, a bolus of $0.12 \mathrm{mg} / \mathrm{kg}$ of $\mathrm{ke}-$ tamine or placebo was administered followed by infusion of $0.65 \mathrm{mg} / \mathrm{kg}$ of ketamine (maximum dose of 58 $\mathrm{mg}$ ) or placebo over 1 hour for a total dose of $0.77 \mathrm{mg}$ / $\mathrm{kg} / \mathrm{hr}$ in subjects receiving ketamine.

\section{Cognitive and Behavioral Measures}

Baseline cognitive and behavioral measurements were collected 30 minutes prior $(-30)$ to the infusion. During the study cognitive testing was conducted at timepoints $+10,+55,+90$, and +120 minutes and behavioral ratings were conducted at +55 and +90 minutes.

Cognitive testing included tasks that assessed attention, free recall of categorically related words, and recognition memory for categorically related words. These tasks have been standardized and validated in studies of the effects of different classes of drugs in a number of patient populations (Weingartner et al. 1982, 1983a, 1983b, 1992). Subjects were read a list of 12 categorically related words at a 2 -second rate. These words are typical exemplars of categories such as vegetables, fruit, and animals. Six of the 12 words were read once, and six of the words were repeated after the presentation of at least two other words. The subjects were instructed to listen to the words and identify when a word was repeated by saying "repeat." To accomplish this task subjects must be able to attend to the words and hold them in working memory for as long as 34 seconds. After an activity-filled 2-minute delay, subjects were asked to recall freely all words. After a 30-second activity-filled delay, subjects were then read a new list of 24 words from the same category. This list contained all 12 of the previous words and 12 distractor items. Subjects were asked to identify the origin of each as "new" (not on previous list) or "old" (on previous list).

Behavioral changes were assessed by administration of the 18-item Brief Psychiatric Rating Scale (BPRS; Overall and Gorham 1962). The BPRS scores were analyzed in total and by analysis of the empirically derived factors for thought disorder, withdrawal-retardation, anxiety-depression, and hostility-suspiciousness (Hedlund and Vieweg 1980).

\section{Data Analysis}

Data were analyzed by using repeated-measures analyses of variance (ANOVAs) with time as the within-subjects variable and drug condition as the independent variable. To account for sphericity, the Greenhouse-Geisser conservative $F$-test was used to interpret the ANOVA. Post hoc $t$-tests were conducted when the ANOVA drug $\times$ time interactions were significant. One subject did not complete recognition memory testing at timepoint +55 during the ketamine infusion day and this subject's recognition memory data was not included.

To test the hypothesis that ketamine-induced attentional deficits were not responsible for free recall and recognition memory impairments, analyses of covariance were conducted with attention as a covariate at the time of peak drug effect ( +55 mins).

To test the hypothesis that ketamine-induced mem- 
ory impairments were not related to ketamine's psychotomimetic effects, Pearson correlational coefficients were conducted between the changes in recall and recognition scores and the changes in BPRS scores (total score and individual factors) at the time of peak drug effect ( +55 minutes). For each item ketamine effects were calculated by subtraction of placebo day score from the active day score at +55 minutes. All correlations were two-tailed. Analyses of covariance could not be conducted with BPRS scores because of the lack of variance in the placebo condition.

\section{RESULTS}

Ketamine produced significant decreases in free recall (Figure 1). The effects of drug $[F(1,14)=9.63, p=.008]$, time $[F(4,56)=5.16, p=.005]$, and the interaction of drug and time $[F(4,52)=4.35, p=.004]$ were significant. Post hoc analysis demonstrated significant decreases in
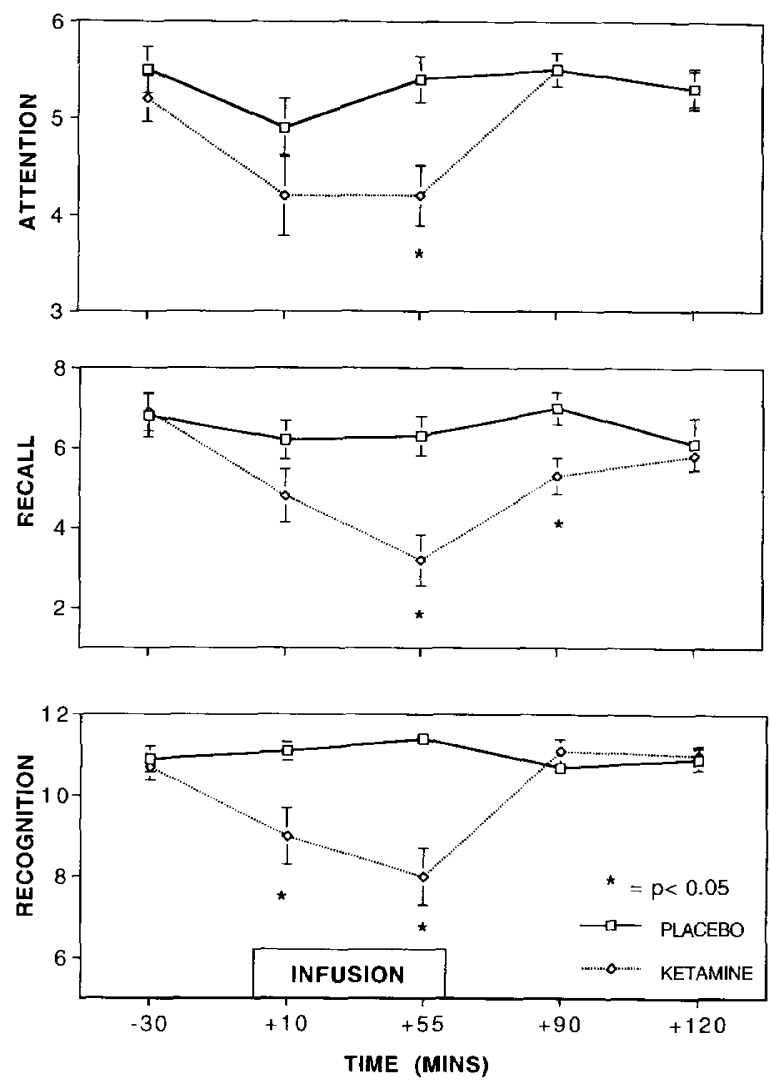

Figure 1. The effects of ketamine (open diamonds) compared with placebo (open squares) on attention, free recall, and recognition memory in 15 healthy controls. Measurements were taken at baseline 30 minutes prior to infusion $(-30)$, at two time points during the infusion $(+10$ and +55$)$, and at 30 and 60 minutes postinfusion $(+90$ and +120$)$. Significant differences between ketamine and placebo are indicated by $*(p<.05)$. free recall at +55 minutes $[F(1,13)=18.79, p=.001]$, and +90 minutes $[F(1,13)=6.25, p=.026]$. Ketamine also produced significant impairments in recognition memory (Figure 1). The effects of drug $[F(1,13)=17.48$, $p=.001)$ and time $[F(4,52)=6.05, p=.001]$ and the interaction of drug and time $[F(4,52)=7.95, p<.001]$ were highly significant. Post hoc analysis showed decreases in recognition memory performance at +10 minutes $[F(1,13)=8.92, p=.01]$ and +55 minutes $[F(1,13)=18.78$, $p=.001]$. Ketamine produced significant, although less robust, decrements in attention (Figure 1). The effects of $\operatorname{drug}[F(1,14)=9.63, p=.008]$, time $[F(4,56)=5.37, p=$ $.003]$, and the interaction of drug and time $[F(4,56)=$ $2.71), p=.05]$ were significant. Post hoc analysis revealed significant deceases in attention scores at +55 minutes $[F(1,14)=8.79, p=.01]$. Examination of individual subjects' cognitive testing revealed that 9 of 15 subjects demonstrated decreases in attention from baseline at +55 minutes of the ketamine infusion. Thirteen of the 15 subjects demonstrated deceases in free recall, and 9 of 14 subjects demonstrated decreases in recognition memory.

Ketamine also produced significant effects on BPRS scores (Table 1). In the repeated-measures ANOVA of BPRS total score, the effects of $\operatorname{drug}[F(1,82)=24.20, p<$ $.001]$, time $[F(2,82)=9.00, p<.001]$, and the interaction of drug condition and time $[F(2,81)=10.37, p<.001]$ were highly significant. Upon analysis of BPRS factors, ketamine produced significant effects on the thought disorder and withdrawal retardation factors. For thought disorder, effects of drug $[F(1,82)=39.65, p<.001]$, time $[F(2,82)=25.30, p<.001]$, and the interaction of drug and time $[F(2,81)=24.99, \mathrm{p}<.001]$ were significant. For withdrawal-retardation effects of drug $[F(1,82)=$ $21.58, p<.001]$, time $[F(2,82)=11.21, p<.001]$, and the interaction of drug and time $[F(2,81)=8.12, p<.001)$ were significant. For anxiety-depression the effect of drug was significant $[F(1,82)=7.51, p=.007]$, but no significant effects were seen by time or on the interaction of drug and time. For hostility-suspiciousness the ANOVA revealed no significant effects. Examination of individual subjects' behavioral data revealed that 13 of 15 subjects demonstrated increases from baseline in the thought disorder subscale score. Fourteen of 15 subjects demonstrated increases in withdrawal-retardation. Six of $15 \mathrm{sub}-$ jects demonstrated increases in anxiety-depression, and 1 of 15 had increases in hostility-suspiciousness.

To characterize further the behavioral response to ketamine, individual items within the thought disorder and withdrawal-retardation factors were examined. Within the thought disorder factor, ratings on item \#4 [conceptual disorganization and disorganized speech $\left(X_{\text {ket }}=\right.$ $\left.\left.2.9 \pm 1.1, X_{\mathrm{pbo}}=1.0 \pm 0.0, t=6.42, p<.001\right)\right]$ and on item \#15 [unusual thought content $\left(X_{\text {ket }}=2.2 \pm 1.1\right.$, $\left.\left.X_{\mathrm{pbo}}=1.0 \pm 0.0, t=4.29, p<.001\right)\right]$ were significantly higher on ketamine at peak drug effect ( +55 minutes). 
Table 1. Psychotomimetic Effects of Ketamine in Normal Controls $(n=15)$

\begin{tabular}{|c|c|c|c|c|c|}
\hline & $-30 \mathrm{Min}$. & +55 Min. & +90 Min. & $F(\mathrm{DF}=2,81)^{a}$ & $p^{a}$ \\
\hline \multicolumn{6}{|l|}{ BPRS total $b$} \\
\hline Ketamine & $19.3 \pm 0.4$ & $27.5 \pm 1.6^{c}$ & $21.5 \pm 1.4$ & 10.4 & $<.001$ \\
\hline Placebo & $19.1 \pm 0.7$ & $18.7 \pm 0.4$ & $18.7 \pm 0.3$ & & \\
\hline \multicolumn{6}{|c|}{ Thought disorder } \\
\hline Ketamine & $3.0 \pm 0.0$ & $6.3 \pm 0.6^{c}$ & $3.5 \pm 0.2$ & 24.9 & $<.001$ \\
\hline Placebo & $3.0 \pm 0.0$ & $3.0 \pm 0.0$ & $3.0 \pm 0.0$ & & \\
\hline \multicolumn{6}{|c|}{ Withdraw / retardation } \\
\hline Ketamine & $3.3 \pm 0.1$ & $6.6 \pm 0.6^{c}$ & $4.6 \pm 0.5$ & 8.1 & .001 \\
\hline Placebo & $3.3 \pm 0.2$ & $3.5 \pm 0.2$ & $3.5 \pm 0.2$ & & \\
\hline \multicolumn{6}{|c|}{ Hostility/suspiciousness } \\
\hline Ketamine & $3.3 \pm 0.2$ & $3.5 \pm 0.5$ & $3.3 \pm 0.3$ & 0.1 & .90 \\
\hline Placebo & $3.1 \pm 0.1$ & $3.1 \pm 0.1$ & $3.1 \pm 0.1$ & & \\
\hline \multicolumn{6}{|c|}{ Anxiety/depression } \\
\hline Ketamine & $3.5 \pm 0.2$ & $3.9 \pm 0.3$ & $3.1 \pm 0.1$ & 2.3 & .10 \\
\hline Placebo & $3.3 \pm 0.2$ & $3.1 \pm 0.1$ & $3.0 \pm 0.0$ & & \\
\hline
\end{tabular}

There was no significant difference between ratings on item \#12 [hallucinations $\left(X_{\text {ket }}=1.2 \pm 0.5, X_{\text {pbo }}=1.0 \pm\right.$ $0.0, t=1.38, p=0.190)]$. Within the withdrawal-retardation factor, ratings on item \#3 [emotional withdrawal $\left.\left(X_{\text {ket }}=2.1 \pm 0.9, X_{\text {pbo }}=1.2 \pm 0.4, t=3.67, p=.003\right)\right]$, item \#13 [motor retardation $\left(X_{\text {ket }}=2.3 \pm 0.9, X_{\text {pbo }}=1.2 \pm\right.$ $0.4, t=5.91, p<.001)$ ], and item \#16 [blunted affect $\left.\left(X_{\text {ket }}=2.2 \pm 0.9, X_{\text {pbo }}=1.1 \pm 0.3, t=4.94, p<.001\right)\right]$ were significantly higher on ketamine than placebo at 55 minutes.

Ketamine-induced effects on free recall and recognition remained significant after the effects of attention were covaried for as the drug-by-time interaction was significant for both free recall $[F(1,12)=6.55, p=0.25]$ and recognition memory $[F(1,13)=7.05, p=.025]$.

Ketamine's effects on free recall were not significantly related with ketamine's effects on BPRS total score $(r=-.28, p=.31)$, thought disorder $(r=-.31, p=$ $.26)$, or withdrawal-retardation $(r=-.11, p=.71)$. Ketamine's effects on recognition memory were not significantly related to BPRS total score $(r=-.28, p=.34)$, thought disorder $(r=-.41, p=.14)$, or withdrawal-retardation ( $r=.02, p=.96$; Figure 2$)$ either. Ketamine's effects on free recall significantly correlated with ketamine's effects on recognition memory $(r=.64, p=.01)$. Ketamine's effects on thought disorder did not significantly correlate with ketamine's effects on withdrawalretardation $(r=.06, p=.83)$.

\section{DISCUSSION}

This study demonstrated that ketamine disrupted normal subject's performance of an attention task, impaired
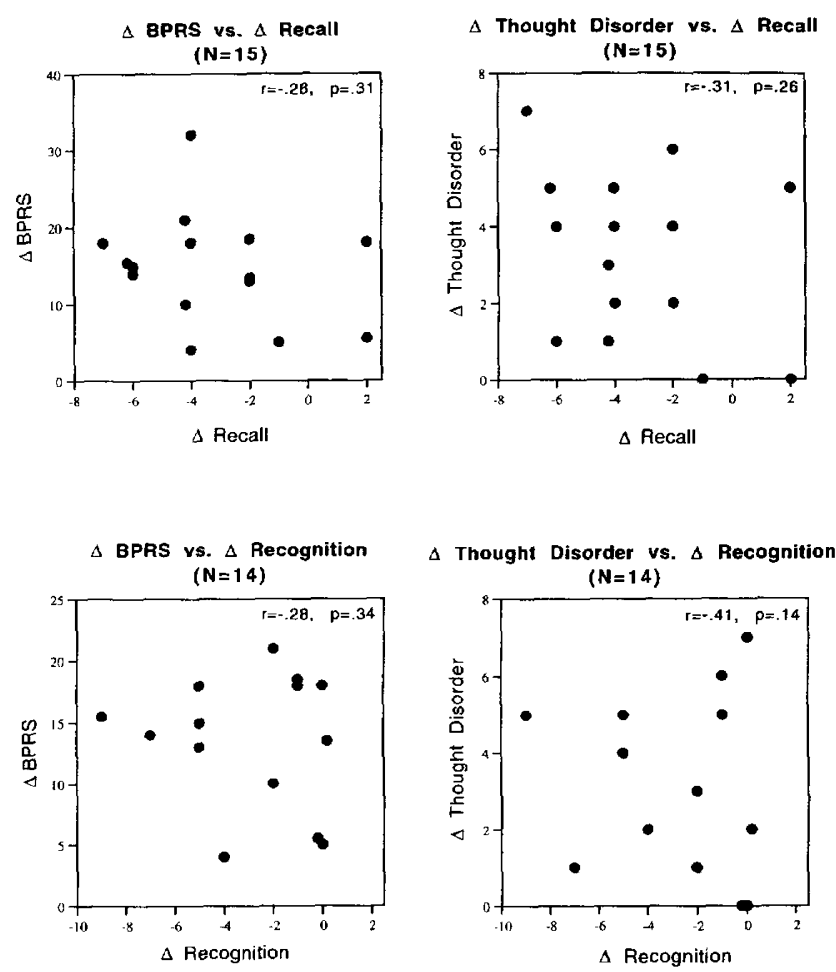

Figure 2. Correlational analyses of changes in cognitive function and behavior ratings between ketamine and placebo at peak effect of ketamine ( +55 minutes) and 15 healthy controls ( $N=14$ for recognition memory). There were no significant correlations between ketamine-induced changes in free recall and changes in Brief Psychiatric Rating Scale (BPRS) total score or BPRS Thought Disorder subscale scores. Similarly, correlations between ketamine-induced changes in recognition memory and changes in BPRS total score or BPRS Thought Disorder subscale scores were not significant. 
their free recall of recently presented items, and decreased their ability to recognize correctly the origin of these items. Concomitantly, ketamine produced significant levels of thought disorder and withdrawal-retardation in our healthy volunteers. Ketamine's effects on free recall and recognition memory were not secondary to ketamineinduced effects on attention. Moreover, ketamine's effects on memory were not significantly related to ketamineinduced changes in psychosis ratings. These data suggest that ketamine has direct effects on free recall and recognition memory.

Previous clinical studies have reported ketamine-induced impairments in cognitive performance. In six subjects, Oye et al. (1992) found a dose-dependent reduction in recall of a set of eight pictures presented after a bolus administration of ketamine. Another study (Harris et al. 1975) demonstrated impairments in recall of word pairs after a $0.4-\mathrm{mg} / \mathrm{kg}$ bolus of ketamine followed by $0.2-\mathrm{mg} / \mathrm{kg}$ doses every 15 minutes. Ghoneim et al. (1985) reported diminished recall of a 24-item list after $0.25-\mathrm{mg} / \mathrm{kg}$ and $0.50-\mathrm{mg} / \mathrm{kg}$ injections of ketamine. Krystal et al. (1994) administered a constant infusion of $0.5 \mathrm{mg} / \mathrm{kg}$ of ketamine over 40 minutes to 17 normal volunteers and found that ketamine impaired delayed recall of three items. Although the contribution of the attentional or psychotomimetic effects of ketamine on memory was not specifically addressed, two studies (Harris et al. 1975; Krystal et al. 1994) have also reported impairments in attention with changes in behavior and perception. Our study suggests that these attentional and behavioral disturbances were not related to the specific memory impairments induced by ketamine.

Ketamine-induced memory deficits could be secondary to a disruption of acquisition of new material or an inability to retrieve material that has been successfully acquired and stored. If ketamine selectively impaired retrieval, decrements in free recall would occur because free recall of successfully acquired material is primarily a measure of retrieval ability. Recognition memory, however, would be relatively preserved as the recognition paradigm involves a second presentation of each item to the subject and therefore does not require the subject to self-generate a retrieval strategy for searching memory. If ketamine produced acquisition deficits, recognition memory would be as equally disrupted as free recall because the presence of retrieval cues would not assist in recognition of items not successfully acquired and unavailable for retrieval. Our data suggest that ketamine preferentially impairs acquisition as ketamine produced profound decrements in both free recall and recognition performance. Support for this interpretation is provided by a small clinical study that found that ketamine produced acquisition deficits with a sparing of retrieval ability (Oye et al. 1992) and a preclinical study demonstrating NMDA antagonist-induced deficits in acquisition but not performance (i.e., retrieval) of spatial learning tasks (Ohno et al. 1994). These acquisitional impairments may be secondary to ketamine's ability to inhibit LTP induction in the hippocampus (Zhang and Levy 1992), and further study of LTP and human memory will be valuable in identifying precisely the molecular mechanisms underlying human memory.

These human data are consistent with basic studies implicating NMDA receptor function in cognition (Shapiro and Caramanos 1990; Flood et al. 1992; Murata and Kawasaki 1993; Lee et al. 1993). There remains the possibility that ketamine produces cognitive impairments via interactions with nonNMDA receptor sites. Ketamine's affinity for the intrachannel site within the NMDA receptor (Hampton et al. 1982), however, is several-fold higher than its affinities for monoamine transporter sites (Smith et al. 1981), the sigma receptor (Oye et al. 1991), the mu opiate receptor (Smith et al. 1980), and acetylcholinesterase (Cohen et al. 1974). Byrd et al. (1987) administered naloxone, atropine, or chlorpromazine in combination with ketamine or PCP and found that these selective agents for opiate, cholinergic, and monoamine receptors, respectively, did not antagonize ketamine and PCP-induced behavioral effects, suggesting that ketamine's behavioral effects are mediated by its interaction with the PCP site. In vitro studies have found that ketamine only reduces non-NMDA voltagegated potassium currents at concentrations much higher than reported in patients anesthetized with ketamine (Rothman 1988). This suggests that low doses of NMDA antagonists will enhance selectivity for the PCP site (Javitt and Zukin 1991).

This study also provides support for the idea that administration of NMDA antagonists produces a clinical syndrome similar, though not identical, to schizophrenia (Javitt and Zukin 1991). As shown in this and other studies (Luby et al. 1959; Krystal et al. 1994), NMDA antagonists produce many of the "positive" (i.e., thought disorganization, bizarre thought content, perceptual distortions) and "negative" (i.e., restricted affect, withdrawalretardation) symptoms of schizophrenia (though ketamine did not commonly induce hallucinations or paranoid delusions in our healthy volunteers). In addition, our data suggest that NMDA receptor antagonism also reproduces aspects of the memory dysfunction observed in schizophrenia. Both treated and untreated schizophrenic patients have been found to suffer specific deficits in free recall and recognition memory not accounted for by alterations in attention or arousal level (Saykin et al. 1991; Tamlyn et al. 1992). This cognitive profile is similar to the cognitive profile observed in our normal subjects treated with ketamine. The use of ketamine as a pharmacological probe of NMDA function may therefore yield new insights into the specific cognitive dysfunction of schizophrenia.

In summary, our study suggests that ketamine, an 
NMDA antagonist, directly interferes with specific aspects of human cognition and that these effects are not significantly related to psychotic or attentional changes. Ketamine, in contrast to agents like the benzodiazepines that produce profound decrements in both attention and memory (Weingartner et al. 1992), may therefore represent a unique pharmacological probe of cognition and NMDA receptor function. Further work with ketamine, then, should prove valuable in the understanding of human cognition and the neuropsychiatric disorders that involve cognitive deficits.

\section{REFERENCES}

Abraham WC, Mason SE (1988): Effects of the NMDA receptor/channel antagonists CPP and MK801 on hippocampal field potentials and long-term potentiation in anesthetized rats. Brain Res 462:40-46

Byrd LD, Standish LJ, Howell LL (1987): Behavioral effects of phencyclidine and ketamine alone and in combination with other drugs. Eur J Pharmacol 144:331-341

Cohen ML, Chan SL, Bhargava HN, Trevor AJ (1974): Inhibition of mammalian brain acetylcholinesterase by ketamine. Biochem Pharmacol 23:1647-1652

Endicott I, Spitzer RL (1978): A diagnostic interview: The Schedule for Affective Disorders and Schizophrenia. Arch Gen Psychiatr 35:837-844

Flood JF, Morley JE, Lanthorn TH (1992): Effect on memory processing by D-cycloserine, an agonist of the NMDA/ glycine receptor. Eur J Pharmacol 221:249-254

Ghoneim MM, Hinrichs JV, Mewaldt SP, Petersen RC (1985): Ketamine: Behavioral effects of subanesthetic doses. J Clin Psychopharmacol 5:70-77

Hampton RY, Medzihradsky F, Woods JH, Dahlstrom PJ (1982): Stereospecific binding of 3H-phencyclidine in brain membranes. Life Sci 30:2147-2154

Harris EW, Ganong AH, Cotman CW (1984): Long-term potentiation in the hippocampus involves activation of N-methyl-d-aspartate receptors. Brain Res 323:132-137

Harris JA, Biersner RJ, Edwards D, Bailey LW (1975): Attention, learning, and personality during ketamine emergence: A plot study. Anesth Analg 54:169-172

Hedlund JL, Vieweg BW (1980): The Brief Psychiatric Rating Scale (BPRS): A comprehensive review. J Oper Psychiatr 11:48-64

Javitt DC, Zukin SR (1991): Recent advances in the phencyclidine model of schizophrenia. Am J Psychiat 148:13011308

Krystal JH, Karper LP, Seibyl JP, Freeman GK, Delaney R, Bremner JD, Heninger GR, Bowers MB Jr, Charney DS (1994): Subanesthetic effects of the noncompetitive NMDA antagonist, ketamine, in humans: Psychotomimetic, perceptual, cognitive, and neuroendocrine responses. Arch Gen Psychiatr 51:199-214

Lee EYH, Lee CP, Wang HI, Lin WR (1993): Hippocampal CRF, NE, and NMDA system interactions in memory processing in the rat. Synapse 14:144-153

Luby ED, Cohen BD, Rosenbaum G, Gottlieb JS, Kelley R
(1959): Study of a new schizophrenomimetic drug--sernyl. Arch Neurol Psychiatr 81:363-369

Moretti RJ, Hassan SZ, Goodman LI, Meltzer HY (1984): Comparison of ketamine and thiopental in healthy volunteers: Effects on mental status, mood, and personality. Anesth Analg 63:1087-1096

Morris RGM, Anderson E, Lynch GS, Baudry M (1986): Selective impairment of learning and blockade of longterm potentiation by an N-methyl-D-aspartate receptor antagonist, AP5. Nature 319:774-776

Murata S, Kawasaki K (1993): Common and uncommon behavioral effects of antagonists for different modulatory sites in the NMDA receptor/channel complex. Eur J Pharmacol 239:9-15

Ohno M, Yamamoto T, Watanabe S (1994): Intrahippocampal administration of a glycine site antagonist impairs working memory performance of rats. Eur J Pharmacol 253: 183-187

Olney JW, Labruyere J, Price MT (1989): Pathological changes induced in cerebrocortical neurons by phencyclidine and related drugs. Science 244:1360-1362

Overall JE, Gorham DR (1962): The brief psychiatric rating scale. Psychol Rep 10:799-812

Oye I, Hustveit O, Moberg ER, Pausen O, Skoglund LA (1991): The chiral forms of ketamine as probes for NMDA receptor function in humans. In Kameyama $T$, Nabeshima T, Domino EF (eds), NMDA Receptor Related Agents: Biochemistry, Pharmacology, and Behavior, Ann Arbor, MI, NPP Books, pp 381-389

Oye I, Paulsen O, Maurset A (1992): Effects of ketamine on sensory perception: Evidence for a role of N-methyl-Daspartate receptors. J Pharmacol Exp Ther 260:1209-1213

Pandit SK, Kothary SP, Kumar SM (1980): Low dose intravenous infusion technique with ketamine. Anaesthesia 35:669-675

Rothman S (1988): Noncompetitive N-methyl-D-aspartate antagonists effect multiple ionic currents. J Pharmacol Exp Ther 246:137-142

Saykin AJ, Gur RC, Gur RE, Mozley PD, Mozley LH, Resnick SM, Kester DB, Stafiniak P (1991): Neuropsychological function in schizophrenia. Arch Gen Psychiatry 48:618624

Shapiro ML, Caramanos Z (1990): NMDA antagonist MK801 impairs acquisition but not performance of spatial working and reference memory. Psychobiology 18: 231243

Smith DJ, Pekoe GM, Martin LL, Coalgate B (1980): The interaction of ketamine with the opiate receptor. Life Sci 26:789-795

Smith DJ, Azzaro AJ, Zaldivar SB, Palmer S, Lee HS (1981): Properties of the optical isomers and metabolites of ketamine on the high affinity transport and catabolism of monoamines. Neuropharmacology 20:391-396

Tamlyn D, McKenna PJ, Mortimer AM, Lund CE, Hammond S, Baddeley AD (1992): Memory impairment in schizophrenia: Its extent, affiliations and neuropsychological character. Psychol Med 22:101-115

Weingartner HJ, Langer D, Grice J, Rapoport J (1982): Acquisition and retrieval of information in amphetaminetreated hyperactive children. Psychiatr Res 6:21-29 
Weingartner HJ, Rudorfer MV, Buchsbaum MS, Linnoila M (1983a): Effects of serotonin on memory impairments produced by ethanol. Science 221:472-473

Weingartner HJ, Grafman J, Boutelle W, Kayne W, Martin PR (1983b): Forms of memory failure. Science 221:380-382

Weingartner HJ, Hommer D, Lister RG, Thompsom K,
Wolkowitz O (1992): Selective effects of triazolam on memory. Psychopharmacology 106:341-345

Zhang DX, Levy WB (1992): Ketamine blocks the induction of LTP at the lateral entorhinal cortex-dentate gyrus synapses. Brain Res 593:124-127

Zukin SR, Zukin RS (1979): Specific [3H]phencyclidine binding in rat central nervous system. Proc Natl Acad Sci 76:5372-5376 